Article

\title{
Evaluation of an Analytical Model in the Prediction of Machining Temperature of AISI 1045 Steel and AISI 4340 Steel
}

\author{
Jinqiang Ning *(1) and Steven Y. Liang * \\ George W. Woodruff School of Mechanical Engineering, Georgia Institute of Technology, 801 Ferst Drive, \\ Atlanta, GA 30332-0405, USA \\ * Correspondence: jinqiangning@gatech.edu (J.N.); steven.liang@me.gatech.edu (S.Y.L.); \\ Tel.: +1-774-420-4365 (J.N.)
}

Received: 25 September 2018; Accepted: 20 October 2018; Published: 24 October 2018

\begin{abstract}
This paper evaluates a physics-based analytical model in the prediction of machining temperature of AISI 1045 steel and AISI 4340 steel. The prediction model was developed based on the Johnson-Cook constitutive model (J-C model) and mechanics of the orthogonal cutting process. The average temperatures at two shear zones were predicted by minimizing the difference between calculated stresses using the J-C model and calculated stresses using the mechanics model. In this work, (1) the influence of input Johnson-Cook model constants, cutting force, and chip thickness on the accuracy of predictions are investigated with sensitivity analyses, in which multiple sets of available J-C constants and varying cutting force and chip thickness are used for the temperature prediction in machining AISI 1045 steel. The larger the input deviation, the larger prediction deviation. The temperature at the primary shear zone is more susceptible to the deviation of inputs than the temperature at the secondary shear zone. (2) The machining temperatures are also predicted in machining AISI 4340 steel using cutting tools with various specifications to demonstrate its predictive capability. Good agreements are observed upon validation to available experimental data in the literature. (3) Lastly, the advantage and limitation of the temperature model are discussed with comparison other analytical temperature models. Considering the reliable and easily measurable input requirements and sufficient predictive capability, this temperature model can be employed for effective and efficient machining temperature prediction.
\end{abstract}

Keywords: sensitivity analysis; temperature prediction; Johnson-Cook constitutive model; mechanics of the orthogonal cutting

\section{Introduction}

Machining is an important manufacturing methodology because of its precision, fast processing speed, and applicability to a broad class of materials. Conventional machining processes and non-conventional machining processes such as laser-assisted machining [1] and electrically assisted machining [2-4] have been widely used to transform bulk materials into products with desired geometry and functionality. Elevated temperature in conventional machining has a negative influence on tool performance, tool life, and the quality of machined parts because it softens tool materials and increases diffusion. It is well-known that the plastic deformation at the primary shear zone (PSZ) and the friction at the tool-chip interface (secondary shear zone or SSZ) are two principal heat sources in orthogonal cutting. Previous works have made considerable progress in modeling the temperature distribution in the machining process. Experimental approaches, numerical approaches, and analytical approaches have been developed in the past. 
Experimental approaches using intrinsic thermocouples (alternatively names tool-work thermocouples), embedded thermocouples, radiation pyrometers, metallographic techniques, and a method using fine powders of constant melting temperature have been reported for the temperature measurements of tool and workpiece. The details of temperature measurement techniques can be found in the literature [5,6]. Machining temperature measurement is challenging and difficult because of the complex contact phenomena between the cutting tool and workpiece, and restricted accessibility during the process.

Numerical approaches were developed based on the finite element method (FEM) for the modeling of the machining process. Steady state condition was enforced in the prediction of temperatures using a FEM model [7]. The geometrically complex cutting tool was used in the simulation of the milling process, which yielded an estimation of a specific cutting coefficient [8]. Influence of the cutting tool edge roundness on the temperature distribution in orthogonal cutting process was investigated with FEM model [9]. Influence of the multi-layer tool coatings on the temperature distribution was investigated with FEM model [10]. Laser-assisted machining was also investigated with FEM models [11-13]. Although numerical approaches have made considerable progress in modeling the machining process, the expensively computational cost is still a major drawback. In addition, experimental measurements of chip morphology, machining force, and temperature, and residual stress were often needed in the numerical approaches for the purpose of calibration and validation.

Analytical approaches were also developed to predict the machining process. The shear and ploughing coefficients were used to predict machining force in the milling process [14]. CAM software was integrated to predict machining forces in three-axis milling and five-axis milling [15]. Orthogonal cutting configuration was commonly enforced to simplify the developed models. Chip formation model, as originally proposed by Oxley, was modified to predict force and temperature in the orthogonal cutting process, in which machining temperatures at PSZ and SSZ were assumed to be uniform, and they were calculated using heat partition equations [16]. Another analytical model base on energy balance on the controlled volume was developed to predict transient cutting temperature with calculated heat flux from input cutting forces [17]. The model based on energy balance was further developed using insulated boundary condition to simplify the input requirements and improve the computational efficiency [18]. Komanduri, R. et al. developed an analytical model considering the effect of shear plane heat source at PSZ and the effect of frictional heat source at SSZ [19]. The temperature rise due to the shear plane heat source and the frictional heat source were solved by moving oblique band source solution [20] and a modified moving band solution (chip side) and stationary rectangular heat source solution (tool side) [21] respectively. The model based on two heat sources was future developed with the assumption of non-uniform heat intensity and partition ratio to improve prediction accuracy [22]. Regression analysis and neural network analysis were also employed to predict the tool-chip interface temperature [23]. The complex mathematic equations and the iterative solving algorithm reduce the computational efficacy of the aforementioned analytical models.

Ning J. et al. presented an original analytical model to predict the average temperatures at PSZ and SSZ in the orthogonal cutting process. This temperature model was developed based on the Johnson-Cook constitutive model (J-C model) and mechanics of the orthogonal cutting process [24]. J-C model was employed in the temperature model because it is effective, simple and easy-to-use. J-C model constants (J-C constants), cutting force, and chip thickness were used as inputs. However, the influence of input J-C constants, cutting force and chip thickness on the temperature prediction was not investigated. Multiple sets of $\mathrm{J}-\mathrm{C}$ constants are available in the literature, in which the J-C constants were identified from different experimental approaches, numerical approaches, and analytical approaches [25-29]. The vibration and limitation of the measuring equipment cause the variations of cutting force and chip thickness [30-32]. The advantages and limitations of the temperature model have not been fully investigated. 
In this work, (1) the influence of input J-C constants, cutting force, and chip thickness on the accuracy of temperature prediction is investigated. Sensitivity analyses are performed to predict temperatures in machining AISI 1045 steel, in which multiple sets of available J-C constants, varying cutting force, and varying chip thickness are used. (2) The capability of the presented model is further investigated to predict temperatures in machining AISI 4340 (Sweden Grade SS2541) steel using cutting tools with various edge micro-geometries and coatings. (3) The advantages and limitations are discussed based on model input, output and assumptions, implementation issue, and predictive capability. The presented model is compared to other widely used analytical models in the machining process including Oxley's chip formation model and Komanduri's temperature model considering two heat sources. Predicted temperatures are validated by comparing to documented values adopted from literature. Moreover, machining forces and tool wear can be further investigated with available temperatures at two shear zones.

\section{Methodology}

The presented temperature model is developed based on J-C model and mechanics of the cutting process as illustrated in Figure 1. The equivalence between calculated stresses using J-C model and calculated stresses using cutting mechanics yields the estimation of machining temperatures at PSZ and SSZ. Cutting condition parameters (cutting velocity $V$, the width of cut $w$, the depth of cut $t_{1}$, tool face rake angle $\alpha)$, J-C model constants $(A, B, C, m, n)$, cutting force $\left(F_{c}\right)$ and chip thickness $\left(t_{2}\right)$ are given as inputs. The reliable and easily measurable cutting force and chip thickness can be obtained by using a piezoelectric dynamometer and a micrometer respectively [32].

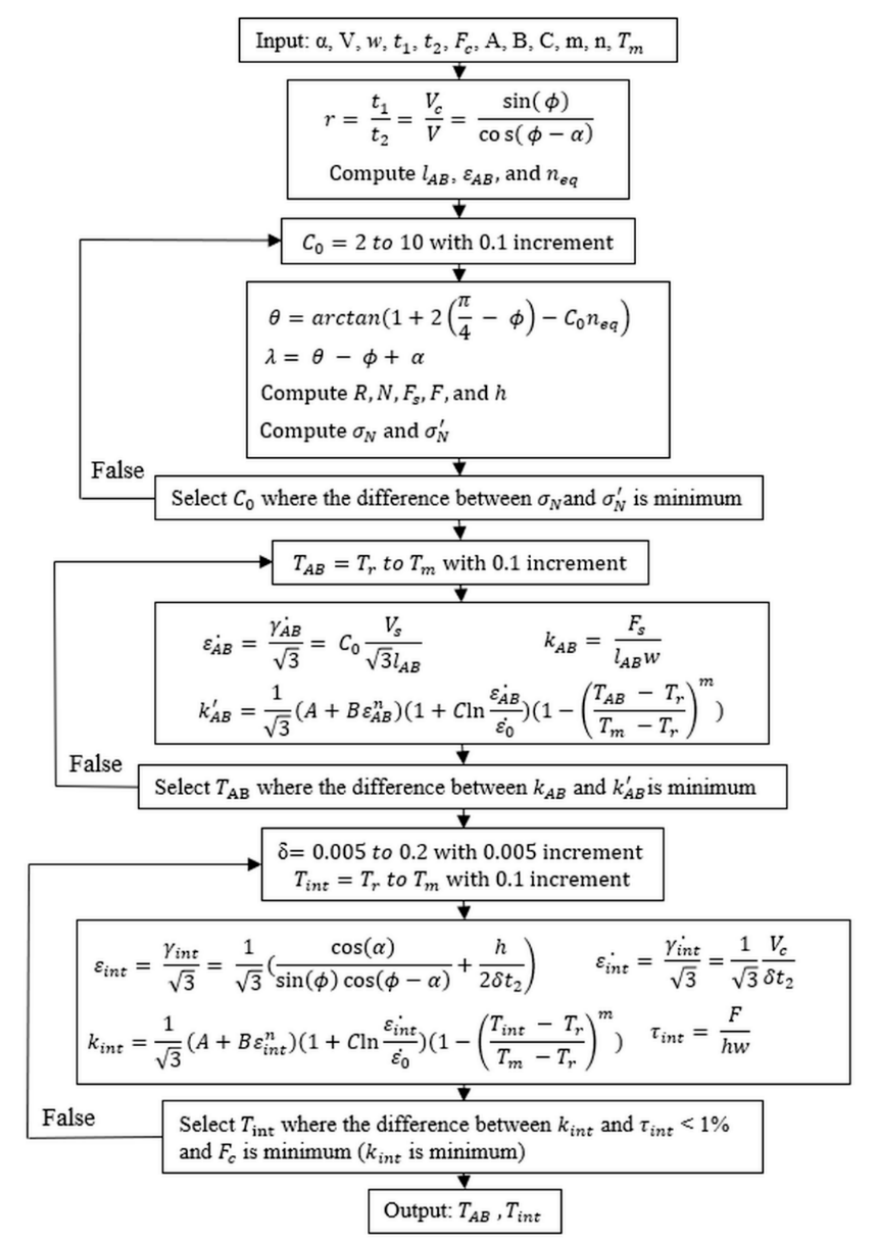

Figure 1. The algorithm of temperature prediction model based on Johnson-Cook (J-C) model and chip formation model [24]. 
J-C model is a semi-empirical constitutive model, which calculates materials flow stress with consideration of strain hardening effect, strain rate hardening effect and thermal softening effect. It is widely used in analytical modeling of force, temperature and residual stress in the machining process. The J-C model is expressed as

$$
\sigma=\left(A+B \varepsilon^{n}\right)\left[1+C \ln \left(\frac{\dot{\varepsilon}}{\dot{\varepsilon_{0}}}\right)\right]\left[1-\left(\frac{T-T_{r}}{T_{m}-T_{r}}\right)^{m}\right]
$$

where the five material constants $A, B, c, n, m$ are the yield stress, the strength coefficient, the strain rate coefficient, the strain hardening coefficient, and the thermal softening coefficient respectively.

The shear angle $(\phi)$ is directly calculated from the chip compression ratio (r) with the assumption of the constant material flow rate at the chip formation area $\left(t_{1} V=t_{2} V_{c}\right)$ as

$$
r=\frac{t_{1}}{t_{2}}=\frac{V_{c}}{V}=\frac{\sin (\phi)}{\cos (\phi-\alpha)}
$$

where $V, V_{c}$ are cutting velocity and chip velocity respectively; $t_{1}$ and $t_{2}$ are the depth of cut and chip thickness respectively.

The shear flow stress at the PSZ can be calculated using the cutting mechanics $\left(k_{A B}\right)$ and J-C model with von Mises yield criterion $\left(k_{A B}^{\prime}\right)$ separately as

$$
\begin{gathered}
k_{A B}=\frac{F_{s}}{l_{A B} w} \\
k_{A B}^{\prime}=\frac{\sigma_{A B}}{\sqrt{3}}=\frac{1}{\sqrt{3}}\left(A+B \varepsilon_{A B}^{n}\right)\left(1+\operatorname{Cln} \frac{\dot{\varepsilon} \dot{A}}{\dot{\varepsilon}_{0}}\right)\left(1-\left(\frac{T_{A B}-T_{r}}{T_{m}-T_{r}}\right)^{m}\right)
\end{gathered}
$$

The average temperature at PSZ $\left(T_{A B}\right)$ is determined by minimizing the difference between the shear flow stress $\left(k_{A B}\right)$ and the shear flow stress $\left(k_{A B}^{\prime}\right)$.

The flow stress at the SSZ can also be calculates using the cutting mechanics $\left(\tau_{\text {int }}\right)$ and J-C model with von Mises yield criterion $\left(k_{i n t}\right)$ separately as

$$
\begin{gathered}
\tau_{\text {int }}=\frac{F}{h w} \\
k_{\text {int }}=\frac{1}{\sqrt{3}}\left(A+B \varepsilon_{\text {int }}^{n}\right)\left(1+C \ln \frac{\varepsilon_{\text {int }}^{\dot{\varepsilon}}}{\dot{\varepsilon}_{0}}\right)\left(1-\left(\frac{T_{\text {int }}-T_{r}}{T_{m}-T_{r}}\right)^{m}\right)
\end{gathered}
$$

The average temperature at the SSZ $\left(T_{i n t}\right)$ is determined by minimizing the difference between the shear flow stress $\left(\tau_{\text {int }}\right)$ and the shear flow stress $\left(k_{\text {int }}\right)$. Details of the calculations of strains $(\varepsilon)$, strain rates $(\dot{\varepsilon})$, lengths of the shear zones $\left(l_{A B} ; h\right)$ at PSZ and SSZ and the strain rate constants $\left(C_{0}\right.$ and $\delta$ ) can be found in previous work [24].

The influence of input J-C constants, cutting force, and chip thickness on the accuracy of temperature prediction is investigated using sensitivity analyses in machining AISI 1045 steel. First, machining temperatures are predicted using multiple sets of available J-C constants adopted from literature. Second, machining temperatures are predicted using varying cutting forces up to $\pm 30 \%$ with the cutting condition and other variables remaining the same. Third, machining temperatures are predicted using varying chip thickness $\pm 30 \%$ with the cutting condition and other variables remaining the same. The predicted temperatures are validated to the documented values in the literature.

The capability of the presented model is investigated with temperature predictions in machining AISI 4340 steel using cutting tools (inserts) with various specifications. Experimental data and cutting tool specifications are adopted from literature, in which five cemented carbide cutting inserts are used in the orthogonal cutting tests. The predicted temperatures are validated to the available experimental values in the literature. 
The advantages and limitations of the presented model are discussed in terms of assumptions, inputs, outputs, and implementation issues with a comparison to other machining predictive models including chip formation model and temperature model based on two heat sources.

\section{Results and Discussion}

In this work, the presented model was employed to predict the average temperatures at PSZ and SSZ in machining AISI 1045 steel and AISI 4340 steel. The machining temperatures were predicted in orthogonal cutting of AISI 1045 steel under various cutting conditions. The influence of input J-C constants, cutting force, and chip thickness on the prediction accuracy was investigated in machining AISI 1045 steel. The model capability was investigated in the machining AISI 4340 steel using cutting tools with various specifications. The advantages and limitations of the presented were discussed in terms of assumptions, inputs, outputs, and implementation issued with a comparison to other commonly used analytical machining models.

The average temperatures at PSZ and SSZ in orthogonal machining of AISI 1045 steel were predicted under various cutting conditions as given in Table 1. J-C constants of AISI 1045 steel obtained from Split Hopkinson Pressure Bar tests were used in the prediction as given in Table 2. The machining forces and temperatures were adopted from literature [32]. The machining forces were validated with experimental forces and good agreements were observed. The machining temperatures were validated with experimental force comparisons because the temperatures were intermediate variables in predicting machining forces.

Table 1. Cutting conditions and machining forces in orthogonal machining of AISI 1045 steel.

\begin{tabular}{ccccccccc}
\hline Material & Test & $\boldsymbol{\alpha} \mathbf{( d e g s )}$ & $\boldsymbol{V}(\mathbf{m} / \mathbf{m i n})$ & $w(\mathbf{m m})$ & $\boldsymbol{t}_{\mathbf{1}}(\mathbf{m m})$ & $\boldsymbol{t}_{\mathbf{2}}(\mathbf{m m})$ & $\boldsymbol{F}_{\boldsymbol{c}}^{R}(\mathbf{N})$ & $\boldsymbol{F}_{\boldsymbol{t}}^{R}(\mathbf{N})$ \\
\hline AISI1045 & 1 & 5 & 200 & 1.6 & 0.15 & 0.31 & 433 & 171 \\
{$[32,33]$} & 2 & 5 & 200 & 1.6 & 0.30 & 0.54 & 773 & 233 \\
& 3 & 5 & 300 & 1.6 & 0.15 & 0.28 & 406 & 136 \\
& 4 & 5 & 300 & 1.6 & 0.30 & 0.69 & 899 & 366 \\
\hline
\end{tabular}

Note: ${ }^{\mathrm{R}}$ denotes documented values that were validated with experimental results.

Table 2. Johnson-Cook model constants of AISI 1045 steel $\left(\dot{\varepsilon_{0}}=1 ; T_{r}=25^{\circ} \mathrm{C} ; T_{m}=1460{ }^{\circ} \mathrm{C}\right)$.

\begin{tabular}{cccccc}
\hline Approach & $\boldsymbol{A} \mathbf{( M P a )}$ & $\boldsymbol{B} \mathbf{( M P a )}$ & $\boldsymbol{C}$ & $\boldsymbol{m}$ & $\boldsymbol{n}$ \\
\hline SHPB [25] & 553.1 & 600.8 & 0.0134 & 1 & 0.234 \\
Naik P. [34] & 552 & 604 & 0.0131 & 0.95 & 0.231 \\
Özel T. [35] & 451.6 & 819.5 & 0.0000009 & 1.0955 & 0.1736 \\
Özel T. CPSO [36] & 546.83 & 609.35 & 0.01376 & 0.94053 & 0.2127 \\
\hline
\end{tabular}

The predicted temperatures using the presented model and documented temperatures are given in Table 3. Good agreements were observed between predicted temperatures and documented temperatures as illustrated in Figure 2. The predicted values are generally larger than their corresponding documented values because the documented values were calculated using heat partition equations $\left(T_{A B}=T_{r}+\eta \Delta T_{S Z} ; T_{i n t}=T_{r}+\Delta T_{S Z}+\psi \Delta T_{M}\right)$, in which the heat partition factors were assumed based on the performance of predicted forces. The heat partition factors were underestimated because (1) the documented forces in literature were smaller than the experimental forces [32]; (2) The positive correlation between machining force and temperature has been reported in references $[37,38]$. 
Table 3. Predicted temperatures and other process variables in orthogonal machining of AISI 1045 steel.

\begin{tabular}{cccccccc}
\hline Test & $\boldsymbol{T}_{\boldsymbol{A B}}\left({ }^{\circ} \mathbf{C}\right)^{\mathbf{R}}$ & $\boldsymbol{T}_{\boldsymbol{A B}}\left({ }^{\circ} \mathbf{C}\right)$ & $\boldsymbol{T}_{\text {int }}\left({ }^{\circ} \mathbf{C}\right)$ & $\boldsymbol{T}_{\text {int }}\left({ }^{\circ} \mathbf{C}\right)$ & $\boldsymbol{\phi}$ (degs) & $\boldsymbol{C}_{\mathbf{0}}$ & $\delta$ \\
\hline 1 & 313.12 & 356.66 & 815.74 & 895.57 & 25.61 & 4.65 & 0.18 \\
2 & 300.77 & 341.59 & 941.15 & 997.29 & 28.84 & 4.28 & 0.15 \\
3 & 306.30 & 333.56 & 891.20 & 964.38 & 28.03 & 4.37 & 0.16 \\
4 & 297.80 & 345.07 & 1018.00 & 1018.23 & 30.12 & 3.77 & 0.02 \\
\hline
\end{tabular}

Note: ${ }^{\mathrm{R}}$ denotes documented values that were validated with experimental results [33].
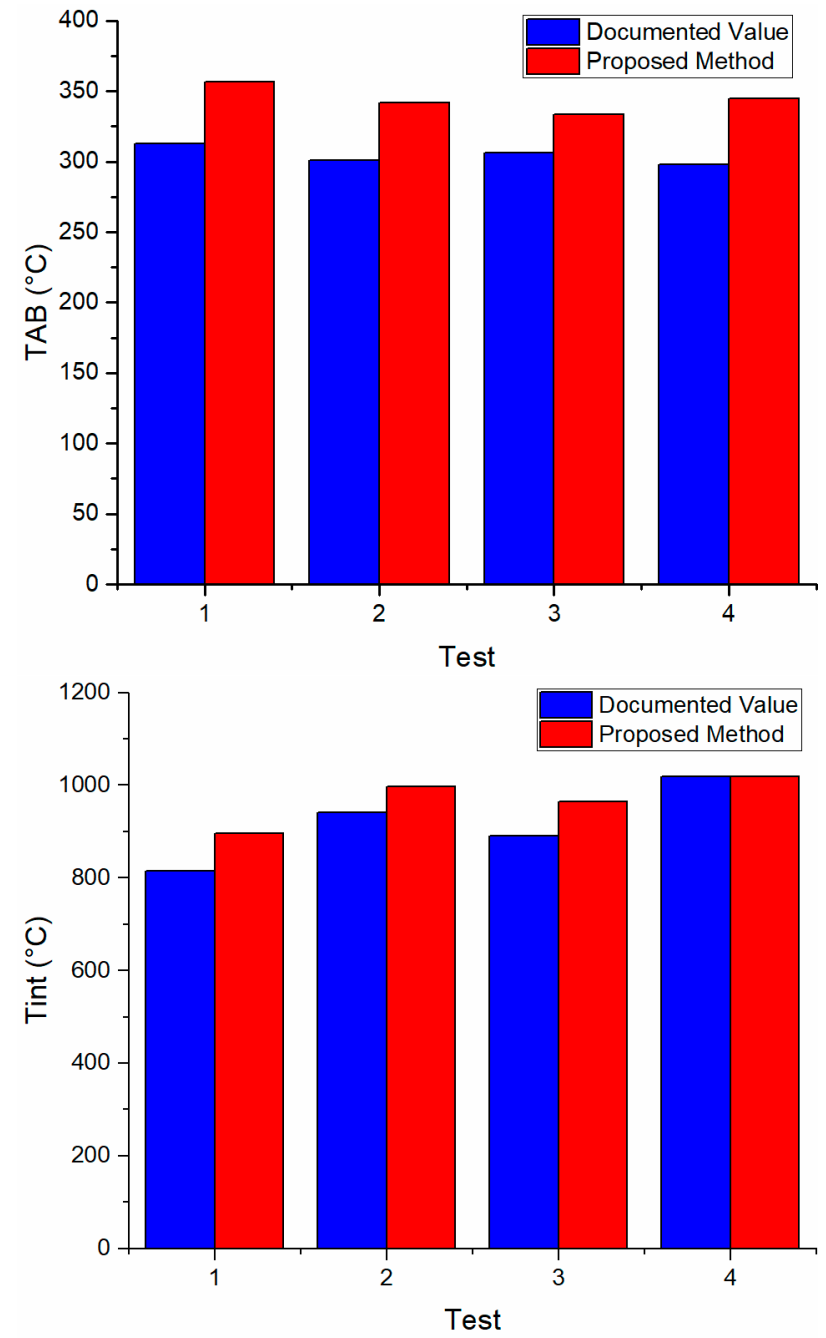

Figure 2. Temperature predictions in orthogonal machining of AISI 1045 steel. $T_{A B}$ (top) and $T_{\text {int }}$ (bottom) denote the average temperatures at primary shear zone (PSZ) and the average temperatures at secondary shear zone (SSZ) respectively.

To investigate the influence of inputs on the accuracy of predicted temperatures in the proposed model, input cutting force and chip thickness in orthogonal cutting of AISI 1045 steel were varied up to $\pm 30 \%$ and multiple sets of available $\mathrm{J}$-C constants were used in the prediction under test 1 cutting condition. The deviation of predicted temperature was calculated as $D=a b s\left(T-T_{r e f}\right) / T_{r e f}$, where $T_{r e f}$ is the documented temperature in the literature. The predicted temperatures with varying cutting force and varying chip thickness are illustrated in Figures 3 and 4 respectively. The minimum deviation for the temperature at PSZ $\left(T_{A B}\right)$ was found at a global minimum location because it was determined when the difference between the shear flow stress $\left(k_{A B}\right)$ and the shear flow stress $\left(k_{A B}^{\prime}\right)$ is minimal. The minimum deviation for the temperature at SSZ $\left(T_{i n t}\right)$ was found at a local minimum 
location because it was determined by minimizing the difference between the shear flow stress $\left(\tau_{\text {int }}\right)$ and the shear flow stress $\left(k_{\text {int }}\right)$ and minimizing cutting force $\left(F_{c}\right)$. The average temperature at the PSZ $\left(T_{A B}\right)$ is more susceptible to the variation of input force and chip thickness than the average temperature at the SSZ $\left(T_{i n t}\right)$. The variation of cutting force and the variation of chip thickness affected the predicted $T_{A B}$ in a similar parabolic trend. The variation of cutting force and the variation of chip thickness affect the predicted $T_{i n t}$ in a similar decreasing trend. The predicted temperatures and other variables with varying cutting force and chip thickness in machining AISI 1045 steel are given in Tables A1 and A2 in Appendix A.

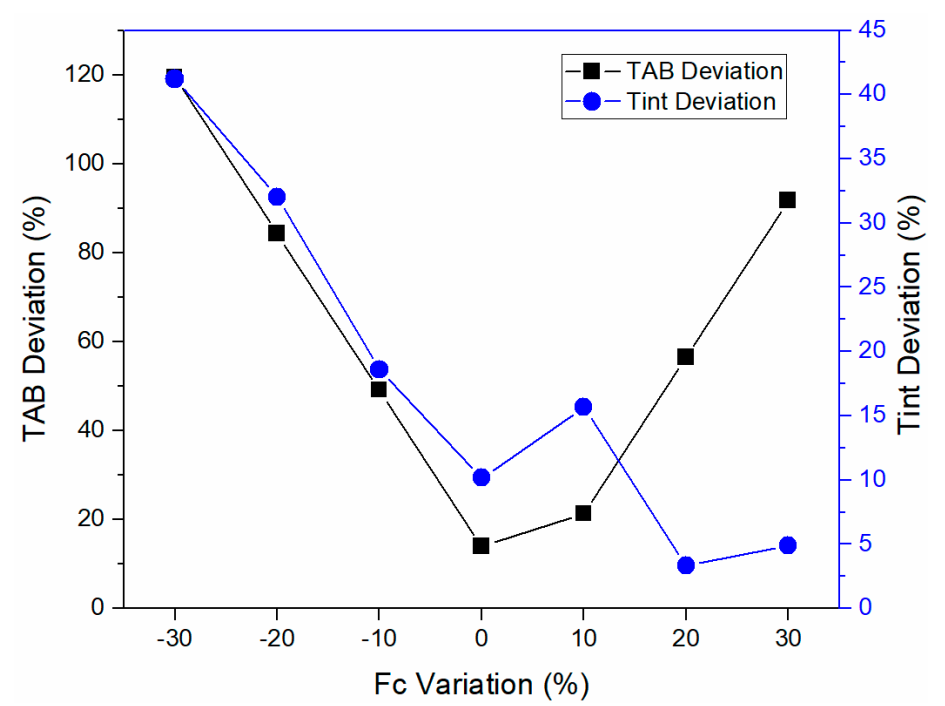

Figure 3. Sensitivity study of input cutting force. Variation of cutting force is $\pm 30 \%$.

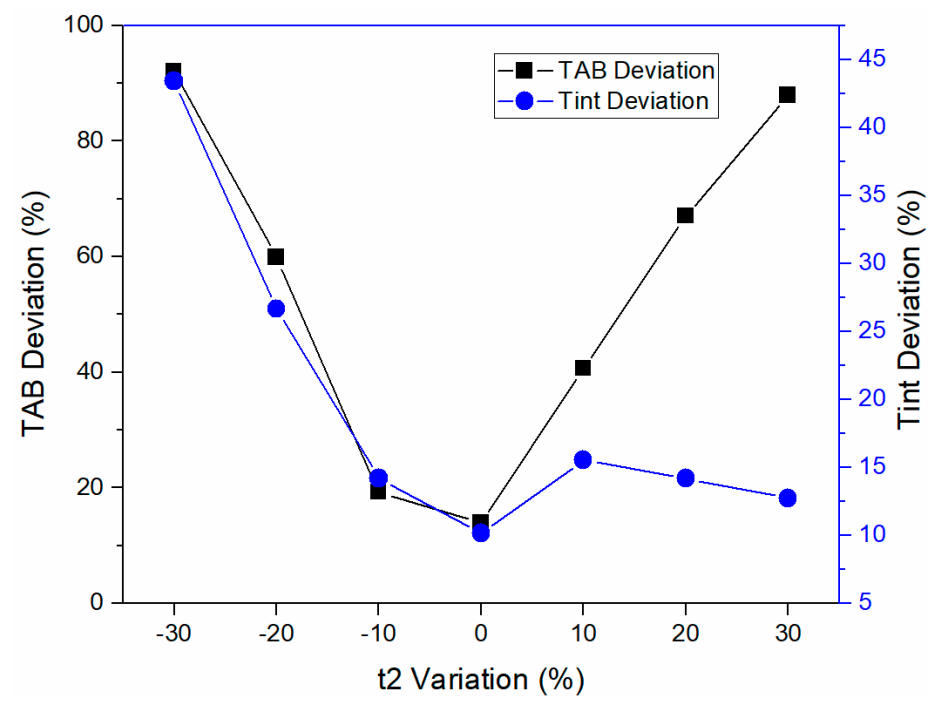

Figure 4. Sensitivity study of input chip thickness. Variation of chip thickness is $\pm 30 \%$.

As illustrated in Figure 5, the predicted temperatures using J-C constants obtained from different approached were in a good agreement with documented values (Set 5) under test 1 cutting condition. The predicted temperatures and other variables with multiple sets of J-C constants are given in Table A3 in Appendix A. 

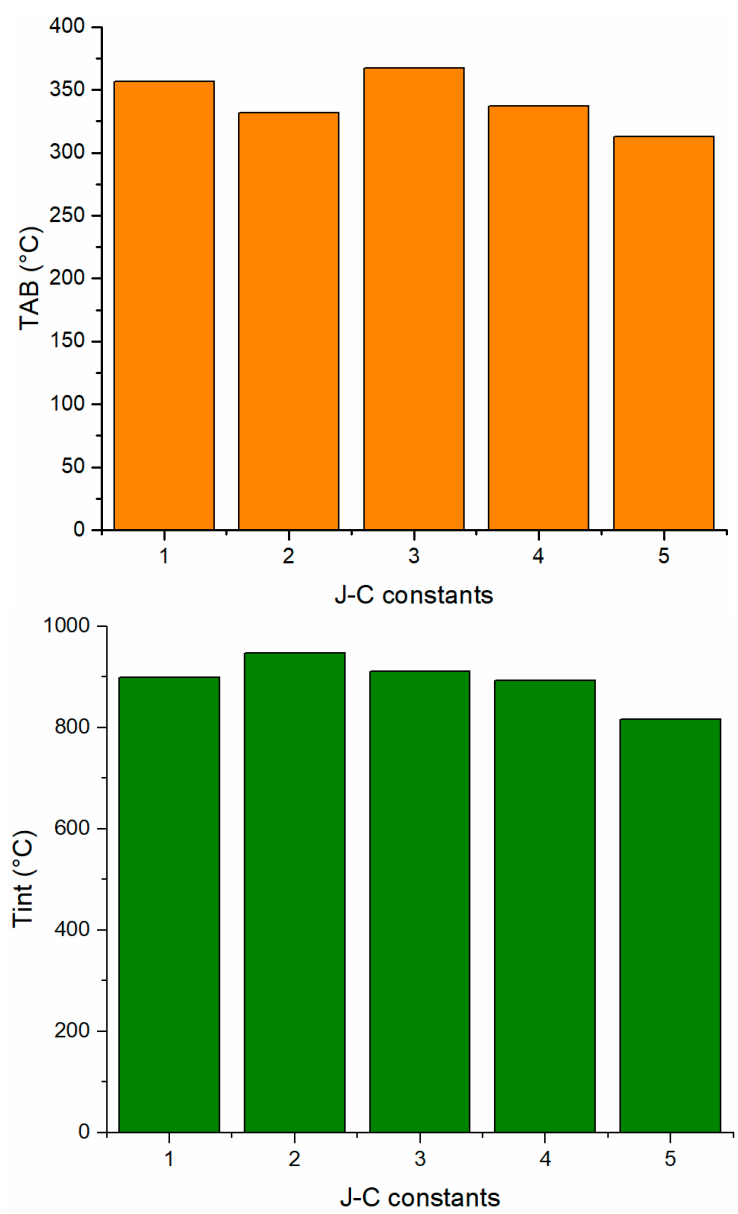

Figure 5. Sensitivity study of input J-C constants. $T_{A B}$ (top) and $T_{\text {int }}$ (bottom) denote the average temperatures at primary shear zone (PSZ) and the average temperatures at secondary shear zone (SSZ) respectively. Set 1 to Set 4 represent prediction with different sets of J-C constants. Set 5 represents documented temperatures.

To investigate the capability of the presented model, the temperatures were predicted in orthogonal cutting of AISI 4340 steel using cutting tools with various specifications. The J-C model constants of AISI 4340 steel are given in Table 4. The tool variants were designated as sharp edge (S), round edge (R), and flank land edge (F), coated sharp edge (SC) and coated round edge (RC) as given in Table 5. The predicted temperatures were validated to the available experimental measurements adopted from literature [39]. The experimental average temperature and experimental maximum temperature at SSZ are as given in Table 6.

Table 4. Johnson-Cook model constants of AISI 4340 steel $\left(\dot{\varepsilon_{0}}=1 ; T_{r}=25^{\circ} \mathrm{C}\right)$ [40].

\begin{tabular}{ccccccc}
\hline Material & $\boldsymbol{A} \mathbf{( M P a )}$ & $\boldsymbol{B} \mathbf{( M P a )}$ & $\boldsymbol{C}$ & $\boldsymbol{m}$ & $\boldsymbol{n}$ & $\boldsymbol{T}_{\boldsymbol{m}}$ \\
\hline AISI 4340 & 850 & 356 & 0.072 & 0.513 & 0.304 & 1427 \\
\hline
\end{tabular}

Table 5. Cutting tool specifications in machining AISI 4340 steel [39].

\begin{tabular}{cccc}
\hline Tool & Edge Preparation & Edge Radius $(\mu \mathrm{m})$ & PVD Coating \\
\hline S & Sharp & $2 \pm 0.7$ & Uncoated \\
R & Round & $25 \pm 4$ & Uncoated \\
F & Flank Land & $2 \pm 0.7$ & Uncoated \\
SC & Sharp & $5 \pm 3$ & TiN $(5 \mu \mathrm{m})$ \\
RC & Round & $28 \pm 3$ & TiN $(5 \mu \mathrm{m})$ \\
\hline
\end{tabular}


Table 6. Machining temperature predictions of AISI 4340 steel $\left(\mathrm{V}=200 \mathrm{~m} / \mathrm{min}, t_{1}=0.1 \mathrm{~mm}\right.$, $\mathrm{w}=4.8 \mathrm{~mm}, \alpha=6 \mathrm{degs}$ ) [39].

\begin{tabular}{ccccccccccc}
\hline Tool & $\boldsymbol{t}_{\mathbf{2}}(\mathbf{m m})$ & $\boldsymbol{F}_{\boldsymbol{c}}(\mathbf{N})$ & $\boldsymbol{F}_{\boldsymbol{t}}(\mathbf{N})$ & $\boldsymbol{T}_{\boldsymbol{A B}}\left({ }^{\circ} \mathbf{C}\right)$ & $\boldsymbol{T}_{\text {int }}\left({ }^{\circ} \mathbf{C}\right)$ & $\boldsymbol{T}_{\text {int }}^{\text {exp }}\left({ }^{\circ} \mathbf{C}\right)$ & $\boldsymbol{T}_{\text {max }}^{\text {exp }}\left({ }^{\circ} \mathbf{C}\right)$ & $\phi(\mathbf{d e g s})$ & $\boldsymbol{C}_{\mathbf{0}}$ & $\delta$ \\
\hline $\mathrm{S}$ & 0.17 & 1085.03 & 537.01 & 171.6 & 785.39 & 807.88 & 843.2 & 31.67 & 5.04 & 0.04 \\
$\mathrm{R}$ & 0.17 & 1175.9 & 812.39 & 123.84 & 834.96 & 813.96 & 859.93 & 31.67 & 5.05 & 0.01 \\
$\mathrm{~F}$ & 0.17 & 1310.84 & 793.12 & 69.9 & 850.86 & 844.51 & 917.83 & 31.67 & 5.05 & 0.01 \\
$\mathrm{SC}$ & 0.2 & 1032.7 & 484.68 & 295.2 & 692.80 & - & 812.32 & 27.22 & 5.89 & 0.12 \\
$\mathrm{RC}$ & 0.17 & 1104.3 & 713.25 & 160.69 & 729.27 & - & 823.9 & 31.67 & 5.04 & 0.07 \\
\hline
\end{tabular}

Note: S, R, F, SC, RC denote sharp tool edge, round tool edge, flank land tool edge, coated sharp tool edge, and coated round tool edge respectively.

The predicted temperatures using uncoated cutting tools (S, R, F specifications) were validated to the experimental average temperature. Good agreements were observed upon validation as shown in Figure 6. The deviations of predicted temperature were due to the deviations of input cutting forces and chip thickness due to the limitation of the measuring equipment and vibration in the machining process [30-32]. The positive correlation between the experimental maximum temperature and experimental average temperature has been reported in the literature. All predicted temperatures were compared to the experimental maximum temperatures. The predicted temperatures using coated cutting tools were smaller than those using uncoated cutting tools, which agreed well with experimental temperatures.

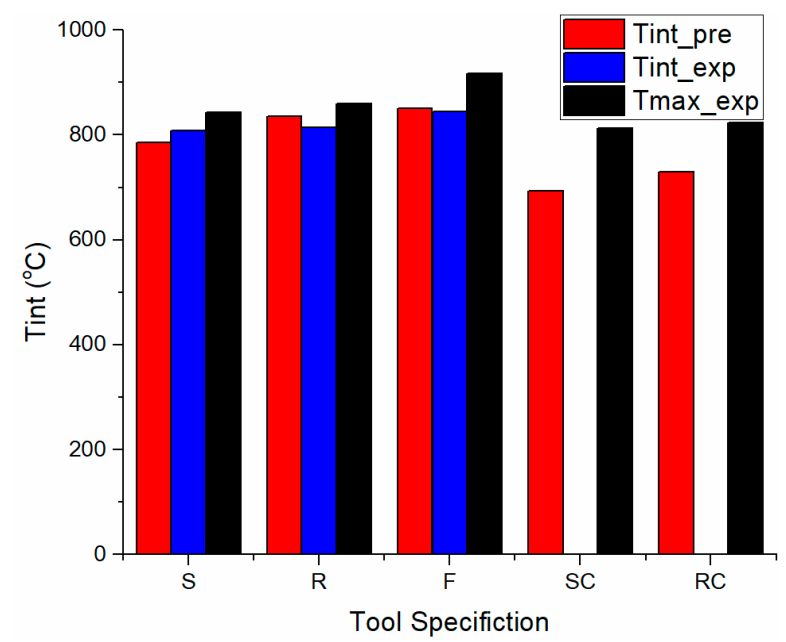

Figure 6. Temperature predictions in orthogonal machining of AISI 4340 steel. Red color, blue color, and black color represent predicted average temperature, experimental average temperature, and experimental maximum temperature at SSZ respectively.

The cutting tool specifications directly affect the cutting force and chip formation in the machining process. The cutting tool specification was considered by using experimental cutting force and chip thickness as inputs. The input of cutting force and chip thickness provided the presented model with promising accuracy in temperature prediction comparing to other models using perfectly sharp cutting tool assumption.

The advantages and limitations of the presented model were discussed with a comparison to other commonly used analytical models in machining temperature prediction. The chip formation model and the temperature model based upon two heat sources at PSZ and SSZ were discussed for comparison purpose. The inputs, output, assumptions, and limitation of three temperature models are summarized as in Table 7. The presented temperature model has the least input requirements and the least number of assumptions. The presented model does not require workpiece materials properties that must be obtained from extensive materials property tests. The prediction of average temperatures at PSZ and SSZ were sufficient for future prediction of force and tool wear [41]. The assumption of the 
perfectly sharp cutting tool in the chip formation model significantly reduces the prediction accuracy in the machining process [33]. The temperature model considering two heat sources needs lengths of PSZ and SSZ as inputs, which are difficult to obtain from experiments because of the complex contact phenomena and restricted accessibility.

Table 7. Comparison of three analytical temperature prediction models.

\begin{tabular}{|c|c|c|c|}
\hline Model & $\begin{array}{l}\text { Presented Temperature } \\
\text { Model [24] }\end{array}$ & $\begin{array}{l}\text { Oxley's Chip Formation } \\
\text { Model [16] }\end{array}$ & $\begin{array}{l}\text { Komanduri's Temperature } \\
\text { Model [19] }\end{array}$ \\
\hline Input & $\begin{array}{l}\text { Cutting condition } \\
\text { parameters; } \\
\text { J-C constants; } \\
\text { cutting force; } \\
\text { chip thickness. }\end{array}$ & $\begin{array}{l}\text { Cutting condition parameters; } \\
\text { J-C constants; } \\
\text { workpiece thermal-physical } \\
\text { properties; } \\
\text { heat partition ratios at PSZ } \\
\text { and SSZ respectively. }\end{array}$ & $\begin{array}{l}\text { Cutting condition } \\
\text { parameters; } \\
\text { cutting forces; workpiece } \\
\text { and tool thermal-physical } \\
\text { properties; } \\
\text { geometry including lengths } \\
\text { and angles of PSZ and SSZ. }\end{array}$ \\
\hline Output & $\begin{array}{l}\text { The average } \\
\text { temperatures at PSZ and } \\
\text { SSZ respectively. }\end{array}$ & $\begin{array}{l}\text { The uniform temperatures at } \\
\text { PSZ and SSZ respectively. }\end{array}$ & $\begin{array}{l}\text { Temperature distribution at } \\
\text { chip formation zone. }\end{array}$ \\
\hline Assumption & $\begin{array}{l}\text { Constant material flow } \\
\text { rate at chip formation } \\
\text { zone; } \\
\text { steady state and plain } \\
\text { strain condition. }\end{array}$ & $\begin{array}{l}\text { Perfect sharp cutting tool; } \\
\text { uniform strain and } \\
\text { temperature at two shear } \\
\text { zones; } \\
\text { steady state and plain strain } \\
\text { condition. }\end{array}$ & $\begin{array}{l}\text { Moving band heat source in } \\
\text { the chip; stationary } \\
\text { rectangular heat source in } \\
\text { the tool; } \\
\text { Imaginary heat source for } \\
\text { boundary conditions. }\end{array}$ \\
\hline $\begin{array}{l}\text { Difficulty and } \\
\text { limitation }\end{array}$ & $\begin{array}{l}\text { Prediction of average } \\
\text { temperature at PSZ and } \\
\text { SSZ respectively. }\end{array}$ & $\begin{array}{l}\text { Determination of heat } \\
\text { partition ratios at PSZ and SSZ } \\
\text { respectively; Prediction of } \\
\text { uniform temperatures at PSZ } \\
\text { and SSZ respectively. }\end{array}$ & $\begin{array}{l}\text { Determination of geometry } \\
\text { including lengths and angles } \\
\text { of PSZ and SSZ. }\end{array}$ \\
\hline
\end{tabular}

Overall, the presented temperature model has demonstrated its effectiveness in the prediction of machining temperatures considering the prediction accuracy, capability and reliable and easily measurable inputs.

\section{Conclusions}

This work evaluates an original temperature prediction model based on J-C model and mechanics of the orthogonal cutting process. The average temperatures at PSZ and SSZ are predicted by minimizing the difference between calculated shear stresses using J-C model and calculated shear stresses using process mechanics. Temperatures were predicted in orthogonal machining of AISI 1045 steel and AISI 4340 steel and then validated to documented values in literature. (1) To investigate the influence of input J-C constants, cutting force, and chip thickness on the prediction accuracy, sensitivity analyses were performed with temperature predictions in machining of AISI 1045 steel. The larger deviations of inputs, the larger deviation of predicted temperatures. The average temperature at the PSZ $\left(T_{A B}\right)$ is more susceptible to the variation of input force and chip thickness than the average temperature at the SSZ $\left(T_{\text {int }}\right)$. J-C constants obtained from different approaches have negligible influence on the predicted temperatures with a comparison to the influence of varying input cutting force and chip thickness. (2) To investigate the capability of the presented model, machining temperatures were predicted in the orthogonal cutting of AISI 4340 steel using cutting tools with various specifications. The cutting tool specification directly affects the cutting force and chip thickness. The tool specification is considered by using cutting force and chip thickness as inputs. (3) Considering the least input requirements, the least number of assumptions and sufficient predictive capability, the presented temperature model can effectively predict machining temperatures. 
Machining forces and tool wear can be further predicted with predicted temperatures. The applicability of the temperature model on a broader class of materials such as titanium alloy and nickel-based alloy can be investigated in the future.

Author Contributions: J.N. performed formal analysis and investigation, extracted, analyzed and validate the data, and wrote the manuscript. S.Y.L. provided general guidance.

Funding: This research was funded by US National Science Foundation grant number CMMI-1404827. The author would like to acknowledge the funding support from the US National Science Foundation.

Conflicts of Interest: The authors declare no conflict of interest.

\section{Appendix A}

Table A1. Predicted temperatures and other variables with varying cutting force input under test 1 cutting condition.

\begin{tabular}{cccccccc}
\hline $\boldsymbol{F}_{\boldsymbol{c}}$ Variation (\%) & $\boldsymbol{T}_{\boldsymbol{A} \boldsymbol{B}}\left({ }^{\circ} \mathbf{C}\right)$ & $\boldsymbol{T}_{\boldsymbol{i n t}}\left({ }^{\circ} \mathbf{C}\right)$ & $\boldsymbol{T}_{\boldsymbol{A B}}$ Deviation (\%) & $\boldsymbol{T}_{\text {int }}$ Deviation (\%) & $\boldsymbol{\phi}(\mathbf{d e g s})$ & $\boldsymbol{C}_{\mathbf{0}}$ & $\delta$ \\
\hline 30 & 26.15 & 775.91 & 91.65 & 4.88 & 25.61 & 4.65 & 0.08 \\
20 & 136.22 & 842.72 & 56.49 & 3.31 & 25.61 & 4.65 & 0.07 \\
10 & 246.44 & 943.44 & 21.29 & 15.65 & 25.61 & 4.65 & 0.03 \\
0 & 356.66 & 898.56 & 13.91 & 10.15 & 25.61 & 4.65 & 0.18 \\
-10 & 466.74 & 967.37 & 49.06 & 18.59 & 25.61 & 4.65 & 0.12 \\
-20 & 576.96 & 1077.07 & 84.26 & 32.04 & 25.61 & 4.65 & 0.04 \\
-30 & 687.18 & 1151.86 & 119.46 & 41.20 & 25.61 & 4.65 & 0.02 \\
\hline
\end{tabular}

Table A2. Predicted temperatures and other variables with varying chip thickness input under test 1 cutting condition.

\begin{tabular}{cccccccc}
\hline $\boldsymbol{t}_{\mathbf{2}}$ Variation (\%) & $\boldsymbol{T}_{\boldsymbol{A} \boldsymbol{B}}\left({ }^{\circ} \mathbf{C}\right)$ & $\boldsymbol{T}_{\boldsymbol{i n t}}\left({ }^{\circ} \mathbf{C}\right)$ & $\boldsymbol{T}_{\boldsymbol{A B}}$ Deviation (\%) & $\boldsymbol{T}_{\text {int }}$ Deviation (\%) & $\boldsymbol{\phi}(\mathbf{d e g s})$ & $\boldsymbol{C}_{\mathbf{0}}$ & $\delta$ \\
\hline 30 & 588.29 & 919.51 & 87.88 & 12.72 & 19.95 & 5.35 & 0.13 \\
20 & 522.85 & 931.47 & 66.98 & 14.19 & 21.57 & 5.15 & 0.08 \\
10 & 440.33 & 942.44 & 40.63 & 15.53 & 23.59 & 4.90 & 0.06 \\
0 & 356.66 & 898.56 & 13.91 & 10.15 & 25.61 & 4.65 & 0.18 \\
-10 & 253.04 & 931.47 & 19.19 & 14.19 & 28.03 & 4.37 & 0.15 \\
-20 & 125.60 & 1033.19 & 59.89 & 26.66 & 30.86 & 4.08 & 0.07 \\
-30 & 25.00 & 1169.81 & 92.02 & 43.40 & 34.49 & 3.77 & 0.07 \\
\hline
\end{tabular}

Table A3. Predicted temperatures and other variables with multiple sets of J-C constants under test 1 cutting condition.

\begin{tabular}{cccccccc}
\hline J-C Constants Set & $\boldsymbol{T}_{\boldsymbol{A B}}\left({ }^{\circ} \mathbf{C}\right)$ & $\boldsymbol{T}_{\boldsymbol{i n t}}\left({ }^{\circ} \mathbf{C}\right)$ & $\boldsymbol{T}_{\boldsymbol{A B}}$ Deviation (\%) & $\boldsymbol{T}_{\text {int }}$ Deviation (\%) & $\boldsymbol{\phi}$ (degs) & $\boldsymbol{C}_{\mathbf{0}}$ & $\delta$ \\
\hline 1 & 356.66 & 898.56 & 13.91 & 10.15 & 25.61 & 4.65 & 0.18 \\
2 & 331.55 & 947.43 & 5.88 & 16.14 & 25.61 & 4.69 & 0.18 \\
3 & 367.43 & 910.53 & 17.34 & 11.62 & 25.61 & 4.99 & 0.15 \\
4 & 336.86 & 892.58 & 7.58 & 9.42 & 25.61 & 5.04 & 0.10 \\
\hline
\end{tabular}

\section{References}

1. Rashid, R.R.; Sun, S.; Wang, G.; Dargusch, M.S. An investigation of cutting forces and cutting temperatures during laser-assisted machining of the Ti-6Cr-5Mo-5V-4Al beta titanium alloy. Int. J. Mach. Tools Manuf. 2012, 63, 58-69. [CrossRef]

2. Egea, A.J.; Rojas, H.A.; Montaña, C.A.; Echeverri, V.K. Effect of electroplastic cutting on the manufacturing process and surface properties. J. Mater. Process. Technol. 2015, 222, 327-334. [CrossRef]

3. Hameed, S.; Rojas, H.A.; Egea, A.J.; Alberro, A.N. Electroplastic cutting influence on power consumption during drilling process. Int. J. Adv. Manuf. Technol. 2016, 87, 1835-1841. [CrossRef]

4. Hameed, S.; González Rojas, H.A.; Perat Benavides, J.I.; Nápoles Alberro, A.; Sánchez Egea, A.J. Influence of the Regime of Electropulsing-Assisted Machining on the Plastic Deformation of the Layer Being Cut. Materials 2018, 11, 886. [CrossRef] [PubMed] 
5. Da Silva, M.B.; Wallbank, J. Cutting temperature: Prediction and measurement methods-A review. J. Mater. Process. Technol. 1999, 88, 195-202. [CrossRef]

6. Longbottom, J.M.; Lanham, J.D. Cutting temperature measurement while machining-A review. Aircr. Eng. Aerosp. Technol. 2005, 77, 122-130. [CrossRef]

7. Umbrello, D.; Filice, L.; Rizzuti, S.; Micari, F.; Settineri, L. On the effectiveness of finite element simulation of orthogonal cutting with particular reference to temperature prediction. J. Mater. Process. Technol. 2007, 189, 284-291. [CrossRef]

8. Gonzalo, O.; Jauregi, H.; Uriarte, L.G.; de Lacalle, L.L. Prediction of specific force coefficients from a FEM cutting model. Int. J. Adv. Manuf. Technol. 2009, 43, 348-356. [CrossRef]

9. Özel, T.; Zeren, E. Finite element modeling the influence of edge roundness on the stress and temperature fields induced by high-speed machining. Int. J. Adv. Manuf. Technol. 2007, 35, 255-267. [CrossRef]

10. Attia, M.H.; Kops, L. A new approach to cutting temperature prediction considering the thermal constriction phenomenon in multi-layer coated tools. CIRP Ann.-Manuf. Technol. 2004, 53, 47-52. [CrossRef]

11. Kim, D.H.; Lee, C.M. A study of cutting force and preheating-temperature prediction for laser-assisted milling of Inconel 718 and AISI 1045 steel. Int. J. Heat Mass Transf. 2014, 71, 264-274. [CrossRef]

12. Shi, B.; Attia, H.; Vargas, R.; Tavakoli, S. Numerical and experimental investigation of laser-assisted machining of Inconel 718. Mach. Sci. Technol. 2008, 12, 498-513. [CrossRef]

13. Yang, J.; Sun, S.; Brandt, M.; Yan, W. Experimental investigation and 3D finite element prediction of the heat affected zone during laser assisted machining of Ti6Al4V alloy. J. Mater. Process. Technol. 2010, 210, 2215-2222. [CrossRef]

14. Lamikiz, A.; López de Lacalle, L.N.; Sanchez, J.A.; Bravo, U. Calculation of the specific cutting coefficients and geometrical aspects in sculptured surface machining. Mach. Sci. Technol. 2005, 9, 411-436. [CrossRef]

15. Calleja, A.; Alonso, M.A.; Fernández, A.; Tabernero, I.; Ayesta, I.; Lamikiz, A.; López de Lacalle, L.N. Flank milling model for tool path programming of turbine blisks and compressors. Int. J. Prod. Res. 2015, 53, 3354-3369. [CrossRef]

16. Oxley, P.L. The Mechanics of Machining: An Analytical Approach to Assessing Machinability; Ellis Horwood: Chichester, UK, 1989; ISBN 9780745800073.

17. Radulescu, R.; Kapoor, S.G. An analytical model for prediction of tool temperature fields during continuous and interrupted cutting. J. Eng. Ind. 1994, 116, 135-143. [CrossRef]

18. Stephenson, D.A.; Jen, T.C.; Lavine, A.S. Cutting tool temperatures in contour turning: Transient analysis and experimental verification. J. Manuf. Sci. Eng. 1997, 119, 494-501. [CrossRef]

19. Komanduri, R.; Hou, Z.B. Thermal modeling of the metal cutting process-Part III: Temperature rise distribution due to the combined effects of shear plane heat source and the tool-chip interface frictional heat source. Int. J. Mech. Sci. 2001, 43, 89-107. [CrossRef]

20. Hahn, R.S. On the temperature developed at the shear plane in the metal cutting process. J. Appl. Mech.-Trans. ASME 1951, 18, 323.

21. Jaeger, C. Conduction of Heat in Solids; Oxford University Press: Oxford, UK, 1959; ISBN 9780198533689.

22. Huang, Y.; Liang, S.Y. Cutting temperature modeling based on non-uniform heat intensity and partition ratio. Mach. Sci. Technol. 2005, 9, 301-323. [CrossRef]

23. Korkut, I.; Acır, A.; Boy, M. Application of regression and artificial neural network analysis in modelling of tool-chip interface temperature in machining. Expert Syst. Appl. 2011, 38, 11651-11656. [CrossRef]

24. Ning, J.; Liang, S.Y. Prediction of Temperature Distribution in Orthogonal Machining Based on the Mechanics of the Cutting Process Using a Constitutive Model. J. Manuf. Mater. Process. 2018, 2, 37. [CrossRef]

25. Kolsky, H. An investigation of the mechanical properties of materials at very high rates of loading. Proc. Phys. Soc. Sect. B 1949, 62, 676. [CrossRef]

26. Shrot, A.; Bäker, M. Determination of Johnson-Cook parameters from machining simulations. Comput. Mater. Sci. 2012, 52, 298-304. [CrossRef]

27. Agmell, M.; Ahadi, A.; Ståhl, J.E. Identification of plasticity constants from orthogonal cutting and inverse analysis. Mech. Mater. 2014, 77, 43-51. [CrossRef]

28. Ning, J.; Liang, S.Y. Model-driven determination of Johnson-Cook material constants using temperature and force measurements. Int. J. Adv. Manuf. Technol. 2018, 97, 1053-1060. [CrossRef] 
29. Ning, J.; Nguyen, V.; Huang, Y.; Hartwig, K.T.; Liang, S.Y. Inverse determination of Johnson-Cook model constants of ultra-fine-grained titanium based on chip formation model and iterative gradient search. Int. J. Adv. Manuf. Technol. 2018, 99, 1131-1140. [CrossRef]

30. Urbikain, G.; Campa, F.J.; Zulaika, J.J.; De Lacalle, L.N.; Alonso, M.A.; Collado, V. Preventing chatter vibrations in heavy-duty turning operations in large horizontal lathes. J. Sound Vib. 2015, 340, 317-330. [CrossRef]

31. Urbicain, G.; Palacios, J.A.; Fernández, A.; Rodríguez, A.; de Lacalle, L.L.; Elías-Zúñiga, A. Stability prediction maps in turning of difficult-to-cut materials. Procedia Eng. 2013, 63, 514-522. [CrossRef]

32. Ivester, R.W.; Kennedy, M.; Davies, M.; Stevenson, R.; Thiele, J.; Furness, R.; Athavale, S. Assessment of machining models: Progress report. Mach. Sci. Technol. 2000, 4, 511-538. [CrossRef]

33. Aydın, M. Cutting temperature analysis considering the improved Oxley's predictive machining theory. J. Braz. Soc. Mech. Sci. Eng. 2016, 38, 2435-2448. [CrossRef]

34. Naik, P.; Naik, A. Determination of flow stress constants by Oxley's theory. Int. J. Latest Technol. Eng. Manag. Appl. Sci. 2015, 4, 110-116.

35. Özel, T.; Zeren, E. A methodology to determine work material flow stress and tool-chip interfacial friction properties by using analysis of machining. J. Manuf. Sci. Eng. 2006, 128, 119-129. [CrossRef]

36. Özel, T.; Karpat, Y. Identification of constitutive material model parameters for high-strain rate metal cutting conditions using evolutionary computational algorithms. Mater. Manuf. Process. 2007, 22, 659-667. [CrossRef]

37. Xiong, L.; Wang, J.; Gan, Y.; Li, B.; Fang, N. Improvement of algorithm and prediction precision of an extended Oxley's theoretical model. Int. J. Adv. Manuf. Technol. 2015, 77, 1-3. [CrossRef]

38. Karpat, Y.; Özel, T. Predictive analytical and thermal modeling of orthogonal cutting process-Part I: Predictions of tool forces, stresses, and temperature distributions. J. Manuf. Sci. Eng. 2006, 128, 435-444. [CrossRef]

39. M'saoubi, R.; Chandrasekaran, H. Investigation of the effects of tool micro-geometry and coating on tool temperature during orthogonal turning of quenched and tempered steel. Int. J. Mach. Tools Manuf. 2004, 44, 213-224. [CrossRef]

40. Chandrasekaran, H.; M'saoubi, R.; Chazal, H. Modelling of material flow stress in chip formation process from orthogonal milling and split Hopkinson bar tests. Mach. Sci. Technol. 2005, 9, 131-145. [CrossRef]

41. Gibson, A. Tool life and cutting forces when machining XC 45 steel. Int. J. Prod. Res. 1971, 9, $409-421$. [CrossRef] 